\title{
Minerals content of extruded fish feeds containing cricket (Acheta domesticus) and black soldier fly larvae (Hermetia illucens) fractions
}

\author{
F. G. Irungu - C. M. Mutungi • A. K. Faraj $\cdot$ H. Affognon • \\ C. Tanga $\cdot$ S. Ekesi $\cdot$ D. Nakimbugwe $\cdot$ K. K. M. Fiaboe
}

Received: 27 October 2017/ Accepted: 14 February 2018/Published online: 26 February 2018

(C) The Author(s) 2018. This article is an open access publication

\begin{abstract}
Animal food sources provide human beings with minerals considerably in adequate quantities. Fish is an indispensable reliable source of nutrients, as aquaculture is a sector that is fast growing and which provides $50 \%$ of the world's fish production. However, fish production is hampered by the increasing costs of feeds due to the ever rising cost of fish meal, an integral component of fish feeds. Substituting fish meal with cheap, yet highly nutritious ingredients in fish feeds is therefore paramount. This study investigated the effects of substituting fish meal with adult cricket meal (ACM) and black soldier fly meal (BSFM) on minerals content of extruded fish feeds, where four levels of substitution $(0,25,50$ and $75 \%)$ were used. The effect of feed moisture content on minerals was also studied where 20 and $30 \%$ feed moisture levels were used. Leaching effects of the pellets were studied as well. The results showed a significant increase $(P<0.05)$ in the levels of phosphorus and potassium as the level of fish meal substitution increased from 0 to $75 \%$. On the other hand, iron and sodium levels reduced significantly $(P<0.05)$ as the level of fish meal substitution increased. Magnesium content increased with increasing level of substitution with BSFM, but decreased with increasing level of substitution with ACM. Copper, zinc and manganese were not greatly influenced by levels of fish meal substitution. Diets that had zero substitution showed higher leaching effect for most minerals than diets that were substituted with 75\% ACM or BSFM. This study found that both ACM and BSFM can be used to substitute fish meal in fish feeds and obtain adequate mineral profile and low leaching effect.
\end{abstract}

Keywords Fish meal · Substitution $\cdot$ Cricket $\cdot$ Black soldier fly larvae $\cdot$ Minerals $\cdot$ Extrusion

F. G. Irungu $(\bowtie) \cdot$ C. M. Mutungi · A. K. Faraj

Department of Dairy and Food Science and Technology, Egerton University, P. O. Box 536-20115, Egerton, Kenya

e-mail: gichuhofrancis@gmail.com

C. M. Mutungi $\cdot$ C. Tanga $\cdot$ S. Ekesi $\cdot$ K. K. M. Fiaboe

International Centre of Insect Physiology and Ecology, P. O. Box 30772-00100, Nairobi, Kenya

C. M. Mutungi

International Institute of Tropical Agriculture (IITA), Plot NO. 25, Mikocheni Light Industrial Area, Dar es Salaam, Tanzania

H. Affognon

International Crops Research Institute for the Semi-Arid Tropics, BP 320, Bamako, Mali

D. Nakimbugwe

Department of Food Technology and Nutrition, School of Food Technology, Nutrition and Bio-Engineering, Makerere University, P. O. Box 7062, Kampala, Uganda 


\section{Introduction}

Food insecurity is a threat to many nations, especially the developing countries. In fact, $10.9 \%$ of the world's population (795 million people) is undernourished. This situation is worse in the sub-Saharan Africa where Middle Africa and East Africa have 41.3 and $31.5 \%$ of their population being undernourished, respectively (FAO 2015). Animal food sources provide protein of high value as well as a variety of micronutrients such as minerals in adequate quantities (FAO 2012; Murphy and Allen 2003). In addition, nutrients from animal food sources are more bio-available than most plant sources (Trumpo et al. 2001). Fish is one such source that provides $17 \%$ of animal protein to the world's population (Halden et al. 2014). Given the forecasted 9 billion in world population by the year 2050, fish becomes an indispensable reliable source of nutrients as aquaculture is also fast growing (Msangi et al. 2013; Halden et al. 2014; FAO 2014). Fishmeal, an integral ingredient in fish feed is becoming extremely expensive due to fluctuations in its production and this has contributed to high cost of feeds (FAO 2012, 2013, 2014; Njagi et al. 2013). There is thus the need to identify better alternatives to fishmeal. Insects such as crickets (Acheta domesticus) and black soldier fly (Hermetia illucens) have that potential (FAO 2013; Bondari and Sheppard 1981; Makkar et al. 2014), due to their high nutritional profile (Henry et al. 2015; FAO 2010; van Huis 2013), high bio-conversion ratio (Barroso et al. 2014) and their ability to produce less greenhouse gases and to be reared on less land area (Oonincx et al. 2010).

Traditionally, insects have been processed using different methods. For example, after harvest, mopane caterpillar is normally sun dried with the aim of achieving higher shelf life (Mutungi et al. 2017). In China, silkworm pupa, the most widely consumed insect, is normally fried in oil, boiled using water or in some cases milled into powder (Belluco et al. 2013). Other traditional processing methods of edible insects include sun drying, roasting, smoking, boiling as well as removal of unpalatable parts (Rumpold et al. 2014). Sun drying is cheap and easy to carry out. However, it is dependent on weather conditions and therefore is hampered by such climatic conditions as wet weather, strong winds as well as mist and fogs. The majority of these methods have far reaching negative impacts. Drying and toasting of termites and grasshoppers have been attributed to significant decrease in contents of individual vitamins, including pyridoxine, folic acid, ascorbic acid, niacin, riboflavin, retinol and $\alpha$-tocopherol, depending on the insect species (Kinyuru et al. 2010). Additionally, the in vitro digestibility of proteins in tree locust has been shown to decline upon toasting and boiling, as the tannin and phytate content increased as a result of these treatments. According to Afiukwa and Okereke (2013), removal of wings as one of the unpalatable insects' parts reduces the amount of iron that can be obtained from Trinervitermes germinates (termite) — an edible insect from Nigeria. Thus, although these methods have been used to process edible insects in the past, they present a situation where their reliability is questioned (Chakravorty et al. 2014). Extrusion is a modern processing method that can be used to process insects and insects-based products such as fish feeds. It has the benefits of improving the nutritional value of end products, destroying undesirable enzymes and anti-nutritional factors (Nikmaram et al. 2015; Alam et al. 2016; Filipovic et al. 2010) and it has also been shown to enhance the apparent absorption of minerals (Razzaq et al. 2012; Alonso et al. 2001).

Minerals represent a minor proportion in the feeds' composition. However, they are required in almost every aspect of animal metabolism (Alonso et al. 2001; FAO 2017). They are classified either as macro elements, which are needed by the body in large quantities, or micro elements, needed by the body in small quantities (FAO 2017; Thompson et al. 2005). Macro elements include phosphorus, calcium, potassium, magnesium, sodium, chlorine and sulfur, while micro elements are composed of copper, zinc, manganese, iron, cobalt and iodine, among others (FAO 2017; Webster and Lim 2002). Fish requires these elements as they help in several functions such as transmission of nerve impulses, acid-base balance, as enzyme cofactors and activators, normal functioning of muscles, osmoregulation and in the formation of skeletal muscles (FAO 2017; Braga et al. 2016; Hassaan et al. 2013; NRC 1993). Fish may obtain some minerals such as calcium, sodium and potassium readily from the surrounding water environment (FAO 2017; NRC 1993), but cannot get adequate amounts of phosphorus, zinc, iron and copper from water (Oliva-Teles 2012; NRC 2011) and thus these must be supplied by the diet through nutritious feeds (Tang et al. 2012). The aim of this experiment was to study the effects of substituting fish meal with different levels of black soldier fly larvae and cricket meals on the mineral composition of extruded fish feeds. The effects of moisture content on the mineral profile of extrudates were also investigated. 


\section{Materials and methods}

Research site

Extrusion of feeds was done using a small-scale single screw extruder at Bidii Fish Farmers, Luanda-Vihiga County, Kenya. Mineral analyses were carried out at Kenya Agricultural and Livestock Research Organization (KALRO), Njoro, Kenya.

\section{Materials}

Maize germ, sunflower cake, dried cassava chunks, wheat pollard and dried freshwater shrimps were purchased from a local vendor in Luanda town, Vihiga County, Kenya. Blanched and sun-dried adult house crickets (Acheta domesticus L.) were purchased from farmers in Homa Bay County, Kenya, while blanched and sun-dried black soldier fly larvae (Hermetia illucens L.) were obtained from Sanergy Limited, Nairobi, Kenya, a commercial insect rearing farm. Each ingredient was then ground separately into fine meal using a hammermill (Model 4, ARTHUR H. THOMAS, Philadelphia, PA, USA) and finally passed through a $1.0 \mathrm{~mm}$ aperture sieve.

Experimental design

A $2 \times 4 \times 2$ factorial arrangement in a completely randomized design was used. The factors investigated were insect type (two levels; black soldier fly larvae and adult cricket), level of freshwater shrimp meal (FWSM) protein substitution with black soldier fly larvae meal (BSFM) or adult cricket meal (ACM) (four levels: 0, 25, 50 and 75\%), and feed moisture content (two levels: 20 and 30\% on wet weight basis). The experiment was replicated three times.

\section{Feed formulation}

The quantities of the ingredients required to formulate iso-proteinaceous diets (26\% protein; $5 \mathrm{~kg}$ formulation) and the amount of water needed to achieve a required moisture content (on wet weight basis) were calculated using Microsoft Excel ${ }^{\circledR}$ function on Windows 2007 and weighed using an electronic digital weighing scale (Model no.: 7765, Ashton Meyers, China), into a 20-L bucket. These were mixed manually for 2 min and then transferred to a multi-vane paddle mixer (Model: MX-25, Unitech, New Delhi, India) for further mixing for 2 min. The control diet and the insect-based formulations are shown in Table 1.

\section{Extrusion process}

A single screw extruder (Model: DOLLY, Unitech, New Delhi, India), with a screw operating at a speed of $200 \mathrm{rpm}$ was used. The extruder was equipped with a pre-conditioning chamber where blended ingredients were introduced through a manual hopper at a feed rate of $1 \mathrm{~kg} / \mathrm{min}$ and preheated with steam at an inlet pressure of 4 bars for approximately $2 \mathrm{~min}$. The mixture was then channeled into the extrusion jacket that housed a single screw with a barrel length and diameter of 55 and $6 \mathrm{~cm}$, respectively. The extruder was set to operate at $120{ }^{\circ} \mathrm{C}$ and fitted with a die that had a diameter of $2 \mathrm{~mm}$ at the exit. Each extruded batch was collected into separate $20 \mathrm{~L}$ bucket and then dried in a solar tent for about $4 \mathrm{~h}$ to constant weight. About $500 \mathrm{~g}$ of the dried pellets were taken in duplicate and packed into zip-lock bags, which were placed in cool and dry wooden locker boxes for further analysis.

Minerals analyses

Freshwater shrimps, cricket, black soldier fly larvae and extruded sample diets were milled using an oscillating mill (Model: MM400; S/N: 129251116; Retsch, Germany) and weighed using an electronic weighing balance (Model: ABS 220-4; S/N: WB1210455; KERN \& SOHN GmbH, Germany). Mineral contents were then 
Table 1 Inclusion levels of insects' meals in freshwater shrimp meal substitution

\begin{tabular}{|c|c|c|c|c|c|c|c|}
\hline \multirow[t]{2}{*}{ Ingredient } & \multirow[t]{2}{*}{ Control } & \multicolumn{6}{|c|}{ Inclusion level of insects (\%) } \\
\hline & & BSFM25 & BSFM50 & BSFM75 & $\mathrm{ACM} 25$ & ACM50 & ACM75 \\
\hline Maize germ & 19 & 18.5 & 18.1 & 17.6 & 19.2 & 19.4 & 19.6 \\
\hline Sunflower cake & 19 & 18.5 & 18.1 & 17.6 & 19.2 & 19.4 & 19.6 \\
\hline Cassava flour & 5 & 4.9 & 4.8 & 4.6 & 5 & 5.1 & 5.2 \\
\hline Wheat pollard & 28.5 & 27.8 & 27.1 & 26.5 & 28.8 & 29.1 & 29.4 \\
\hline FSWM & 28.5 & 20.9 & 13.6 & 6.6 & 21.6 & 14.5 & 7.3 \\
\hline BSFM & - & 9.5 & 18.4 & 27.1 & - & - & - \\
\hline $\mathrm{ACM}$ & - & - & - & - & 6.3 & 12.5 & 19.1 \\
\hline
\end{tabular}

FWSM freshwater shrimp meal, $B S F M$ black soldier fly meal, $A C M$ adult cricket meal, BSFM25 black soldier fly meal substituting $25 \%$ of the protein supplied by FWSM in the control, BSFM50 black soldier fly meal substituting $50 \%$ of the protein supplied by FWSM in the control, BSFM75 black soldier fly meal substituting $75 \%$ of the protein supplied by FWSM in the control, $A C M 25$ adult cricket meal substituting $25 \%$ of the protein supplied by FWSM in the control, ACM50 adult cricket meal substituting $50 \%$ of the protein supplied by FWSM in the control, ACM75 adult cricket meal substituting $75 \%$ of the protein supplied by FWSM in the control

determined by atomic absorption spectrometry in an atomic absorption spectrophotometer (Model: AA-6300; S/N: A305243009165A; Shimadzu, Japan) after digestion in sulfuric acid and selenium powder. Calcium, potassium, magnesium, sodium, copper, zinc, manganese and iron were measured at wavelengths of 422.7 , 766.5, 285.2, 589.0, 324.8, 213.9, 279.5 and $248.3 \mathrm{~nm}$, respectively. Phosphorus was determined using a UVvisible spectrophotometer (Model; UV-1700; S/N: A11024302429LP; Shimadzu, Japan) and measured through a wavelength of $880 \mathrm{~nm}$.

Leaching activity

For each measurement, three replicates were performed. About $5 \mathrm{~g}$ of sample was weighed and introduced into a $250 \mathrm{~mL}$ measuring cylinder containing $200 \mathrm{~mL}$ distilled water. Aliquots $(5 \mathrm{~mL})$ of the supernatant were drawn after 4, 8, 24 and $48 \mathrm{~h}$ and sodium azide added at a rate of $0.02 \%$ into the tubes containing the aliquots. Mineral analyses were then determined as outlined above.

Statistical analysis

Analysis was done using general linear model procedure (PROC GLM) of the Statistical Analysis System (SAS) software version 9.1.3 (SAS Institute Inc., USA) for analysis of variance (ANOVA). Means were separated using Tukey's HSD (honestly significant difference) test at $P<0.05$ level of significance.

\section{Results}

The mineral profile of freshwater shrimp meal, adult cricket meal and black soldier fly meal

Phosphorus and potassium were significantly $(P<0.05)$ higher in BSFM than in FWSM, though the two elements did not show significant $(P<0.05)$ difference between BSFM and ACM (Table 2). Calcium was significantly $(P<0.05)$ higher in FWSM than both in ACM and BSFM. Magnesium was significantly $(P<0.05)$ higher in BSFM than in FWSM and ACM, while FWSM had significantly $(P<0.05)$ higher magnesium than ACM (Table 2). Sodium, copper and zinc were higher $(P<0.05)$ in both BSFM and ACM than in FWSM. Adult cricket meal showed significantly $(P<0.05)$ higher amounts of manganese than FWSM and BSFM. Iron was higher $(P<0.05)$ in ACM and FWSM than in BSFM (Table 2). 


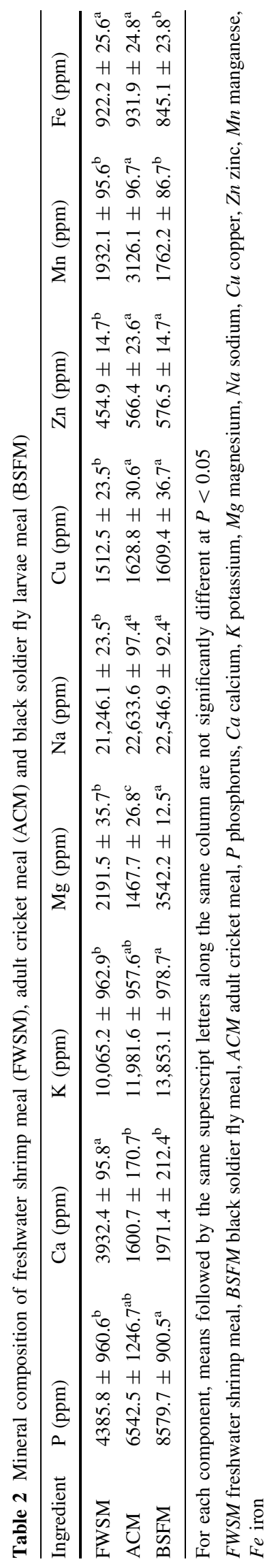


Macro minerals as influenced by different diets extruded at various feed moisture contents

The level of phosphorus in control diets was significantly $(P<0.05)$ lower than in all the insect-based diets (Table 3). As the level of insect substitution increased, so did the level of phosphorus. However, for each level of insect substitution, BSFM-based diets recorded higher values of phosphorus than ACM diets. Moisture content had a significant $(P<0.05)$ effect on phosphorus only for the BSFM50 and BSFM75 diets. The highest level of phosphorus was recorded for the BSFM75 diet that had feed moisture content of $30 \%$.

The control diet that was extruded with feed moisture content of $20 \%$ gave the highest amounts of calcium (Table 3). This level, however, did not show significant $(P<0.05)$ difference with the BSFM25 and ACM 25 diets that were produced at $20 \%$ feed moisture content, or the control diet that had $30 \%$ feed moisture content. The increase in the level of insect substitution led to a corresponding decrease in calcium levels. However, BSFM-based diets had higher calcium levels than the corresponding ACM diets (Table 3). The moisture content was also found to have a significant $(P<0.05)$ influence on calcium, where for each formulation calcium was slightly higher for the extrudates that had $20 \%$ feed moisture content than those that had a feed moisture content of $30 \%$.

The level of potassium appeared to increase with increasing level of fish meal substitution for each insectbased diet (Table 3). This increase was significant $(P<0.05)$, apart from the ACM25 diet that did not show significant $(P<0.05)$ difference with the control diet. Another peculiar observation was that for each diet, the moisture content showed a significant $(P<0.05)$ influence on potassium, where increasing the amount of feed moisture content from 20 to $30 \%$ resulted in a corresponding slight increase in the level of potassium (Table 3).

The amount of available magnesium seemed to increase as the level of fish meal substitution with BSFM increased (Table 3). On the contrary, increasing the level of fish meal substitution with ACM led to a slight decrease in the amount of magnesium. In addition, increasing the level of feed moisture content resulted in

Table 3 Effects of different levels of freshwater shrimp meal substitution with different insect species extruded at different feed moisture contents on phosphorus $(\mathrm{P})$, calcium $(\mathrm{Ca})$, potassium $(\mathrm{K})$, magnesium $(\mathrm{Mg})$ and sodium $(\mathrm{Na})$ of the extrudates

\begin{tabular}{lllllll}
\hline Diet & MC $(\%)$ & $\mathrm{P}(\mathrm{ppm})$ & $\mathrm{Ca}(\mathrm{ppm})$ & $\mathrm{K}(\mathrm{ppm})$ & $\mathrm{Mg}(\mathrm{ppm})$ & $\mathrm{Na}(\mathrm{ppm})$ \\
\hline Control & 20 & $625.9 \pm 19.9^{\mathrm{e}}$ & $15,063.8 \pm 300.6^{\mathrm{a}}$ & $6220.8 \pm 0.7^{\mathrm{e}}$ & $3287.6 \pm 4.5^{\mathrm{e}}$ & $1268.3 \pm 9.2^{\mathrm{a}}$ \\
& 30 & $649.4 \pm 13.5^{\mathrm{e}}$ & $14,476.2 \pm 114.6^{\mathrm{ab}}$ & $6229.4 \pm 2.4^{\mathrm{e}}$ & $3318.9 \pm 5.8^{\mathrm{de}}$ & $1157.8 \pm 31.5^{\mathrm{bc}}$ \\
BSFM25 & 20 & $712.6 \pm 26.6^{\mathrm{d}}$ & $14,696.9 \pm 420.8^{\mathrm{ab}}$ & $6335.4 \pm 0.59^{\mathrm{d}}$ & $3436.1 \pm 31.4^{\mathrm{abcde}}$ & $1223.9 \pm 7.0^{\mathrm{ab}}$ \\
& 30 & $735.9 \pm 39.8^{\mathrm{d}}$ & $10,752.5 \pm 37.8^{\mathrm{cd}}$ & $6341.8 \pm 3.8^{\mathrm{c}}$ & $3519.1 \pm 4.4^{\mathrm{ab}}$ & $1107.6 \pm 19.7^{\mathrm{c}}$ \\
BSFM50 & 20 & $810.6 \pm 10.1^{\mathrm{b}}$ & $13,077.1 \pm 1412.7^{\mathrm{abc}}$ & $6359.5 \pm 8.55^{\mathrm{b}}$ & $3451.9 \pm 13.4^{\mathrm{abcd}}$ & $991.9 \pm 44.4^{\mathrm{d}}$ \\
& 30 & $789.3 \pm 6.7^{\mathrm{c}}$ & $10,386.2 \pm 370^{\mathrm{cd}}$ & $6370.5 \pm 10.4^{\mathrm{b}}$ & $3467.6 \pm 10^{\mathrm{abcd}}$ & $804.7 \pm 7.4^{\mathrm{ef}}$ \\
BSFM75 & 20 & $804.2 \pm 14.9^{\mathrm{b}}$ & $9646.2 \pm 1053.9^{\mathrm{cde}}$ & $6362.5 \pm 2.3^{\mathrm{b}}$ & $3491.6 \pm 60.9^{\mathrm{abc}}$ & $492.1 \pm 16.4^{\mathrm{g}}$ \\
& 30 & $840.9 \pm 4.9^{\mathrm{a}}$ & $8855.8 \pm 218.6^{\mathrm{de}}$ & $6385.9 \pm 5.3^{\mathrm{a}}$ & $3597.5 \pm 49.1^{\mathrm{a}}$ & $442.9 \pm 5.3^{\mathrm{g}}$ \\
ACM25 & 20 & $718.2 \pm 2.3^{\mathrm{d}}$ & $14,613.2 \pm 392.4^{\mathrm{ab}}$ & $6226.3 \pm 3.6^{\mathrm{e}}$ & $3450.3 \pm 42.4^{\mathrm{abcd}}$ & $1145.7 \pm 18.4^{\mathrm{bc}}$ \\
& 30 & $715.9 \pm 23.3^{\mathrm{d}}$ & $12,824.8 \pm 409.3^{\mathrm{bc}}$ & $6243.1 \pm 6.7^{\mathrm{e}}$ & $3383.8 \pm 14.2^{\mathrm{bcde}}$ & $1049.6 \pm 10.1^{\mathrm{d}}$ \\
ACM50 & 20 & $749.4 \pm 6.5^{\mathrm{cd}}$ & $8911.8 \pm 1519.3^{\mathrm{de}}$ & $6359.7 \pm 9.2^{\mathrm{b}}$ & $2956.6 \pm 32.6^{\mathrm{f}}$ & $812.4 \pm 33.6^{\mathrm{ef}}$ \\
& 30 & $769.9 \pm 30.7^{\mathrm{bc}}$ & $4326.1 \pm 39.2^{\mathrm{f}}$ & $6383.5 \pm 8.4^{\mathrm{a}}$ & $2837.6 \pm 38.4^{\mathrm{f}}$ & $717.9 \pm 11.6^{\mathrm{f}}$ \\
ACM75 & 20 & $782.1 \pm 12.7^{\mathrm{bc}}$ & $6439.6 \pm 392.4^{\mathrm{ef}}$ & $6385.3 \pm 0.6^{\mathrm{a}}$ & $3334.8 \pm 12.02^{\mathrm{cde}}$ & $878.2 \pm 4.8^{\mathrm{e}}$ \\
& 30 & $767.8 \pm 21.6^{\mathrm{bc}}$ & $4074.9 \pm 357.7^{\mathrm{f}}$ & $6389.5 \pm 3.3^{\mathrm{a}}$ & $2934.4 \pm 17.8^{\mathrm{f}}$ & $766.09 \pm 18.47^{\mathrm{f}}$
\end{tabular}

Extrusion was done at a barrel temperature of $120{ }^{\circ} \mathrm{C}$ and feed exited through a $2 \mathrm{~mm}$ die

For each component, means followed by the same superscript letters along the same column are not significantly different at $P<0.05$

$M C$ moisture content, $P$ phosphorus, $\mathrm{Ca}$ calcium, $\mathrm{K}$ potassium, $\mathrm{Mg}$ magnesium, $\mathrm{Na}$ sodium, Control $0 \%$ insect substitution of FWSM, BSFM25 black soldier fly meal substituting $25 \%$ of the protein supplied by FWSM in the control, BSFM50 black soldier fly meal substituting 50\% of the protein supplied by FWSM in the control, BSFM75 black soldier fly meal substituting $75 \%$ of the protein supplied by FWSM in the control, ACM25 adult cricket meal substituting 25\% of the protein supplied by FWSM in the control, ACM50 adult cricket meal substituting 50\% of the protein supplied by FWSM in the control, ACM75 adult cricket meal substituting $75 \%$ of the protein supplied by FWSM in control 
higher amounts of magnesium for the control and BSFM diets, but resulted in lower levels of magnesium for the ACM diets (Table 3).

Increasing the level of fish meal substitution with insect meal beyond 25\% resulted in lower levels of sodium, where BSFM50, BSFM75, ACM25, ACM50 and ACM75 diets gave significant $(P<0.05)$ lower amount of sodium than the control diet (Table 3). Moreover, increasing the amount of feed moisture content from 20 to $30 \%$ resulted in a significant $(P<0.05)$ reduction in the amount of sodium (Table 3$)$ for all the diets, apart from BSFM75 whose reduction was not significant $(P<0.05)$.

Micro minerals as influenced by different diets extruded at various feed moisture contents

Copper levels in control diets did not show significant $(P<0.05)$ difference compared with BSFM75, ACM25 and ACM50 diets that were extruded with 30\% feed moisture content (Table 4). The ACM75 diet extruded at both 20 and 30\% feed moisture gave the highest values of copper that significantly $(P<0.05)$ differed from the other formulations. Moisture content showed significant $(P<0.05)$ influence on the level of copper, in that, for each diet, copper levels increased with increasing moisture content (Table 4).

The control diet that had 20\% feed moisture content did not have significant $(P<0.05)$ difference compared with BSFM25 (20\% MC), BSFM50 (20\% MC), BSFM75 (30\% MC), ACM25 (30\% MC) and ACM50 (both 20 and 30\% MC) in amount of zinc (Table 4). Similarly, the control diet that had $30 \%$ feed moisture content did not show significant $(P<0.05)$ difference in amount of zinc, compared with BSFM50 and ACM75 diets that were also extruded at 30\% feed moisture content as well as BSFM75 that had 20\% feed moisture content. ACM75 diet with $20 \%$ feed moisture content gave the highest level of zinc that had significant $(P<0.05)$ difference with all other formulations.

For BSFM diets, there was no definite trend on how different levels of substitution as well as moisture content influenced manganese (Table 4). However, ACM diets showed slight increase in the levels of manganese as feed moisture content was increased from 20 to 30\%. In addition, ACM75 diets gave the highest

Table 4 Effects of different levels of freshwater shrimp meal substitution with different insect species extruded at different feed moisture contents on copper $(\mathrm{Cu})$, zinc $(\mathrm{Zn})$, manganese $(\mathrm{Mn})$ and iron $(\mathrm{Fe})$ of the extrudates

\begin{tabular}{llllll}
\hline Diet & MC $(\%)$ & $\mathrm{Cu}(\mathrm{ppm})$ & $\mathrm{Zn}(\mathrm{ppm})$ & $\mathrm{Mn}(\mathrm{ppm})$ & $\mathrm{Fe}(\mathrm{ppm})$ \\
\hline Control & 20 & $83.7 \pm 0.4^{\mathrm{b}}$ & $158.1 \pm 1.3^{\mathrm{efg}}$ & $14.9 \pm 0.1^{\mathrm{cd}}$ & $356.9 \pm 1.6^{\mathrm{cd}}$ \\
& 30 & $89.9 \pm 1.5^{\mathrm{b}}$ & $181.2 \pm 4.3^{\mathrm{b}}$ & $10.1 \pm 0.2^{\mathrm{ghi}}$ & $376.7 \pm 2.2^{\mathrm{cd}}$ \\
BSFM25 & 20 & $12.5 \pm 1.2^{\mathrm{d}}$ & $159.5 \pm 1.6^{\mathrm{efg}}$ & $12.1 \pm 0.8^{\mathrm{efgh}}$ & $347.4 \pm 30.45^{\mathrm{d}}$ \\
& 30 & $16.8 \pm 2.7^{\mathrm{d}}$ & $145.8 \pm 0.5^{\mathrm{hi}}$ & $13.8 \pm 0.7^{\mathrm{cde}}$ & $355.5 \pm 11.2^{\mathrm{d}}$ \\
BSFM50 & 20 & $19.4 \pm 0.1^{\mathrm{d}}$ & $168.3 \pm 1^{\mathrm{cde}}$ & $18.3 \pm 0.3^{\mathrm{a}}$ & $271.6 \pm 6.4^{\mathrm{e}}$ \\
& 30 & $52.8 \pm 0.5^{\mathrm{c}}$ & $177.4 \pm 1.2^{\mathrm{bc}}$ & $15.6 \pm 0.9^{\mathrm{bc}}$ & $309.7 \pm 15.3^{\mathrm{d}}$ \\
BSFM75 & 20 & $44.8 \pm 0.0^{\mathrm{c}}$ & $171.4 \pm 2.8^{\mathrm{bcd}}$ & $15.6 \pm 0.3^{\mathrm{bc}}$ & $207.8 \pm 11.9^{\mathrm{f}}$ \\
& 30 & $73.1 \pm 5.8^{\mathrm{b}}$ & $161.9 \pm 3.2^{\mathrm{def}}$ & $12.4 \pm 0.5^{\mathrm{efg}}$ & $255.5 \pm 11.2^{\mathrm{e}}$ \\
ACM25 & 20 & $50.9 \pm 8.8^{\mathrm{c}}$ & $143.1 \pm 2.7^{\mathrm{i}}$ & $9.9 \pm 0.3^{\mathrm{hi}}$ & $429.2 \pm 5.3^{\mathrm{b}}$ \\
& 30 & $75.1 \pm 3.4^{\mathrm{b}}$ & $155.3 \pm 0.9^{\mathrm{fgh}}$ & $12.8 \pm 0.2^{\mathrm{def}}$ & $469.6 \pm 5.9^{\mathrm{ab}}$ \\
ACM50 & 20 & $43.5 \pm 4.2^{\mathrm{c}}$ & $153.5 \pm 1.5^{\mathrm{fghi}}$ & $10.6 \pm 0.0^{\mathrm{fghi}}$ & $467.2 \pm 3.2^{\mathrm{ab}}$ \\
& 30 & $75.7 \pm 0.0^{\mathrm{b}}$ & $148.7 \pm 0.8^{\mathrm{ghi}}$ & $12.9 \pm 0.0^{\mathrm{def}}$ & $492.2 \pm 6.4^{\mathrm{a}}$ \\
ACM75 & 20 & $152.3 \pm 3.8^{\mathrm{a}}$ & $199.4 \pm 1.2^{\mathrm{a}}$ & $17.8 \pm 0.2^{\mathrm{ab}}$ & $502.4 \pm 1.7^{\mathrm{a}}$ \\
& 30 & $170.8 \pm 5.6^{\mathrm{a}}$ & $186.1 \pm 2.5^{\mathrm{b}}$ & $18.3 \pm 0.3^{\mathrm{a}}$ & $521.4 \pm 8.2^{\mathrm{a}}$
\end{tabular}

Extrusion was done at a barrel temperature of $120{ }^{\circ} \mathrm{C}$ and feed exited through a $2 \mathrm{~mm}$ die

For each component, means followed by the same superscript letters along the same column are not significantly different at $P<0.05$

$M C$ moisture content, $\mathrm{Cu}$ copper, $\mathrm{Zn}$ zinc, $\mathrm{Mn}$ manganese, $\mathrm{Fe}$ iron, Control 0\% insect substitution of FWSM, BSFM25 black soldier fly meal substituting $25 \%$ of the protein supplied by FWSM in the control, BSFM50 black soldier fly meal substituting $50 \%$ of the protein supplied by FWSM in the control, BSFM75 black soldier fly meal substituting $75 \%$ of the protein supplied by FWSM in the control, ACM 25 adult cricket meal substituting $25 \%$ of the protein supplied by FWSM in the control, ACM50 adult cricket meal substituting $50 \%$ of the protein supplied by FWSM in the control, ACM75 adult cricket meal substituting $75 \%$ of the protein supplied by FWSM in the control 
values of manganese that did not differ significantly $(P<0.05)$ with BSFM50 diets as well as the BSFM75 diet that were extruded at $20 \%$ feed moisture content (Table 4).

An increase in level of fish meal substitution with BSFM resulted in a decrease in final iron content, where BSFM75 diets had significantly $(P<0.05)$ lower levels of iron than the control (Table 4$)$. On the other hand, substitution with ACM resulted in increased levels of iron as the level of substitution increased with all the ACM diets giving significantly $(P<0.05)$ higher levels of iron than the control and BSFM diets. It was also noted that increasing feed moisture content gave a corresponding increase in the amount of iron for all the diets, though this increase was only significant $(P<0.05)$ for the BSFM50 and BSFM75 diets (Table 4$)$.

Leaching activity

Leaching activity was determined on pellets processed from the control formulation and insect meal containing blends at 75\% substitution (BSFM75 and ACM75) and 30\% moisture content, because the three exhibited relatively good mineral profile and have also shown better physico-chemical properties in comparison to other treatments (Irungu et al. 2018). Figure 1 shows the leaching activity of minerals that were studied over a period of $48 \mathrm{~h}$. Phosphorus, calcium, potassium, sodium and manganese were highly leached in the control diet (as shown in Fig. 1 with asterisks), where, during the period studied, the control showed significantly $(P<0.05)$ higher leaching effect as compared to the ACM75 and BSFM75 diets. The leaching of magnesium and zinc was significantly $(P<0.05)$ higher with the ACM75 diets than with BSFM75 and control diets throughout the $48 \mathrm{~h}$ study period. At $4 \mathrm{~h}$, BSFM75 had significantly $(P<0.05)$ lower leached
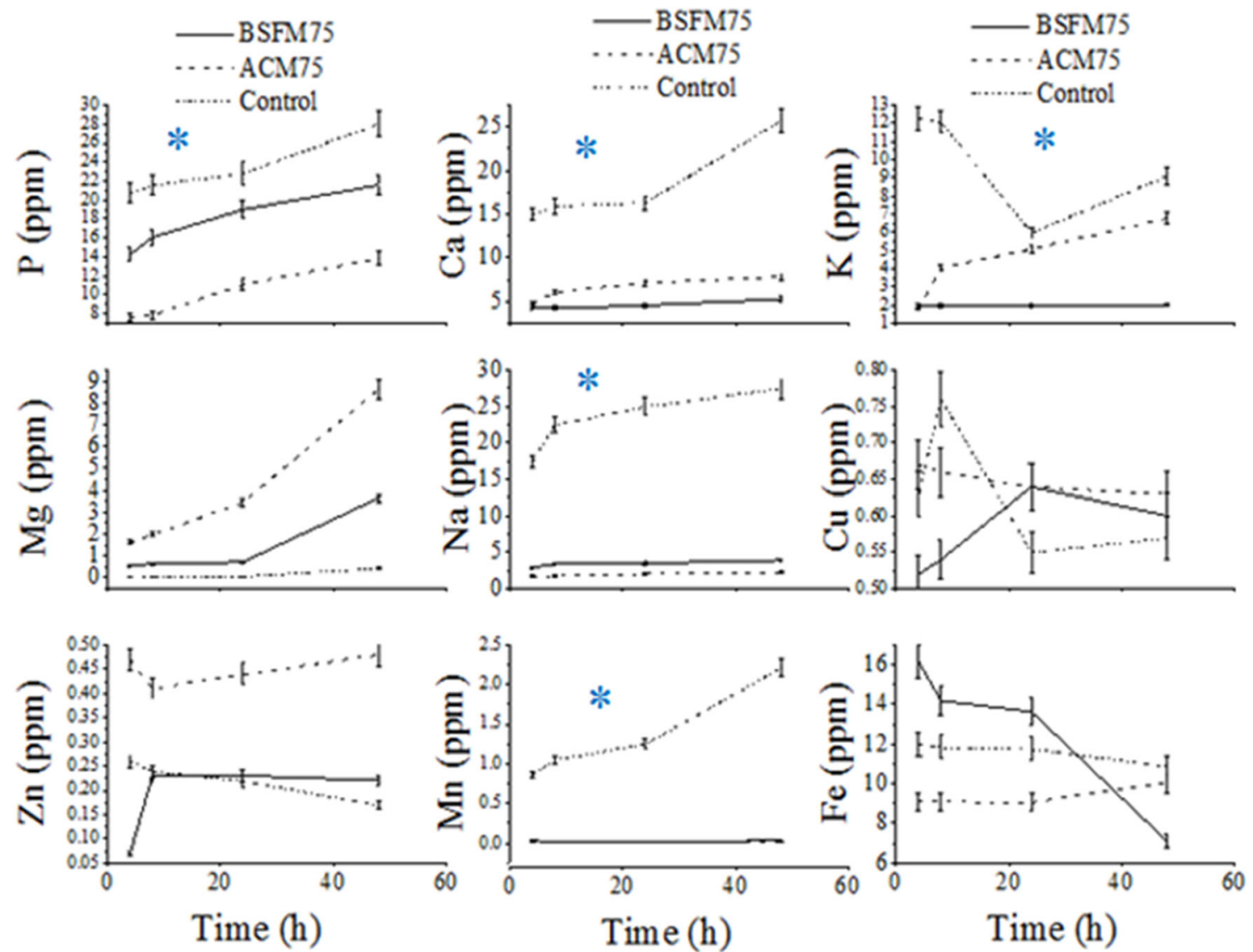

Fig. 1 Leaching activity of minerals ( $P$ phosphorus, $\mathrm{Ca}$ calcium, $\mathrm{K}$ potassium, $\mathrm{Mg}$ magnesium, $\mathrm{Na}$ sodium, $\mathrm{Cu}$ copper, $\mathrm{Zn}$ zinc, $\mathrm{Mn}$ manganese, $\mathrm{Fe}$ iron) in water introduced with pellets extruded from the control blend (round dotted line), black soldier fly larvae meal-containing blend (75\% substitution; BSFM75) (solid line) and adult cricket meal-containing blend (75\% substitution; ACM75) (square-dotted line) adjusted to 30\% moisture content. Parameters with an asterisk show that the control diet gave significant $(P<0.05)$ higher leaching effect than ACM75 and BSFM75 diets 
copper levels than ACM75 and the control, both of which were not significant at the time. However, at 48 h, all the three diets had no significant $(P<0.05)$ difference in the amount of leached copper. At 4,8 and $24 \mathrm{~h}$, BSFM75 had significantly $(P<0.05)$ higher amounts of leached iron levels than the control and ACM75 diets. This scenario changed at $48 \mathrm{~h}$ where BSFM75 showed significantly $(P<0.05)$ low amounts of leached iron than the control and ACM75 diets, both of which were not significant $(P<0.05)$. Another peculiar observation is that while it is expected for the level of leached minerals to increase as time progresses, BSFM75 showed a decreasing trend from 24 to $48 \mathrm{~h}$ with regard to copper, zinc and iron elements. The control also showed the same behavior with zinc and copper, while ACM75 only showed a decreased behavior with copper.

\section{Discussion}

The fact that ACM and BSFM were higher in the majority of minerals than FWSM indicates that the two insects are good sources of minerals and that the two are potential substitutes of FWSM in fish feeds.

Phosphorus and calcium are important minerals required by the fish for healthy bone formation as well as in enhancing the growth performance of fish (FAO 2016; Braga et al. 2016). The two have an antagonistic effect where an inadequate supply of one element affects the availability of the other due to the formation of the calcium-phosphorus complex (Chavez-Sanchez et al. 2000); therefore, both are discussed together. The high values of phosphorus recorded in BSFM-based diets can be attributed to the fact that BSFM had the highest amounts of phosphorus in comparison to ACM and FWSM (Table 2). Newton et al. (1977) and Barker et al. (1998) have also shown that BSFM has higher calcium and phosphorus than ACM. Likewise, the decrease in calcium amounts as the level of substitution increased is attributed to the high values of calcium that are found in FWSM in comparison to BSFM and ACM (Table 2). The low levels of calcium as the feed moisture content was increased to $30 \%$ could be due to the formation of solid bridge complexes (Tumuluru et al. 2011) that hindered the availability of the element. It could also be due to the fact that calcium is highly soluble in water (Nielsen 2010) and thus a lot of it could have been solubilized in water and leached during the extrusion process. On the other hand, phosphorus has poor solubility in water and this could explain why feed moisture content did not have an influence on the amount of available phosphorus. Unlike calcium, phosphorus must be supplied by the feed because fish cannot get it readily from the surrounding water environment (Tessenderlo 2005; Tang et al. 2012). As such, BSFM- and ACM-based diets are good sources of phosphorus, as both resulted in higher levels of phosphorus than the control (100\% freshwater shrimps) diet. However, none of the study diets resulted in minimum requirements for phosphorus for tilapia (Oreochromis Niloticus [L]) and catfish (Clarias gariepinus [Burchell]), which is 5000 ppm and 4500 ppm, respectively (FDKS 2010; FAO 2017), and thus there is need to supplement the feeds with an inorganic source such as dicalcium phosphate so as to improve feed utilization and growth performance. Since calcium and phosphorus have an antagonist effect (Hassaan et al. 2013; FAO 2016), the Ca/P ratio of these diets on growth and development of fish need to be studied.

Potassium is essential in the growth and development of fish, as it regulates acid base balance, intracellular osmotic pressure and is also required for protein and glycogen synthesis (FAO 2017; NRC 1993). The increase in potassium as the level of substitution increased is due to the high potassium levels that are found in both ACM and BSFM in comparison to FWSM (Table 2). The fact that the moisture content influenced potassium levels shows that extrusion has an influence on this element, which could be due to chemical alteration (Singh et al. 2007) and destruction of polyphenols (Alonso et al. 2001) through extrusion at high feed moisture content, which allows phosphorus to become bio-available. Razzaq et al. (2012) also found an increase in potassium amounts of maize extrudates as moisture content was increased. The minimum potassium requirements for tilapia and catfish are 2100-3300 and 2600 ppm, respectively, and thus all our study diets meet these requirements.

Magnesium is required by fish, as it is an essential cartilage and bone component and also stimulates muscle contraction (Jahnen-Dechent and Ketteler 2012; FAO 2017). The decrease in the amount of magnesium as FWSM was substituted with BSFM is due to the higher magnesium content that is found in BSFM than in FWSM (Table 2). Likewise, ACM has lower magnesium content than FWSM (Table 2), the reason why diets substituted with ACM had lower magnesium content than the control diet. The fiber in ACM could have been 
more susceptible to restructuring due to the extrusion process to an extent of promoting chelating effects that could have rendered magnesium unextractable, and thus the low magnesium content in ACM diets (Cheftel 1986). According to FAO (2017), the minimum magnesium requirements for tilapia and catfish are 600-800 and $400 \mathrm{ppm}$, respectively, and all our study diets exceeded these levels. Thus, both BSFM and ACM can be used to substitute FWSM in fish feed and satisfy magnesium requirements for both tilapia and catfish, given that fish does not meet all its magnesium requirements from the surrounding water and feeds must supply the demand (FAO 2017).

Fish need sodium for maintenance of acid base balance and for regulation of osmotic pressure (FAO 2017; Webster and Lim 2002). The sodium in BSFM and ACM may not be readily available as in FWSM, probably due to differences in their structural formation, and this could explain why substituting FWSM with BSFM and ACM resulted in low amounts of sodium. Extrusion at high temperature and high moisture content may have led to the formation of phenolic complexes that changed the chemical structure of the compounds, thus rendering sodium unextractable (Alonso et al. 2001). In addition, high feed moisture content may have lowered the glass transition temperature, leading to the formation of solid bridges (Tumuluru 2014) that resulted in dense products that made sodium unavailable. There is little information on the minimum sodium requirements for both tilapia and catfish and thus it is impossible to conclude whether our study diets (especially insect-based diets) can successfully substitute fish meal and meet the sodium demand for these fishes.

Copper is directly involved in enzymes activity such as dopamine hydroxylase and cytochrome oxidase (Watanabe et al. 1997) and also acts as catalyst for some enzymes (Camire et al. 1990). The higher values of copper in the ACM75 diet than BSFM and control diets is due to the higher copper amounts that were found in ACM in comparison to BSFM and FWSM (Table 2). The increase in copper as feed moisture content increased could be due to the ability of water to increase the contact area of feed particles through van der Waals forces (Tumuluru 2014) and thus increasing the availability of copper. In addition, water used in extrusion could have had traces of copper, which led to more amount of the element as moisture content was increased to $30 \%$. Wheat, one of the ingredients used, has also been shown to influence copper levels (Singh et al. 2007). All the study diets met the minimum requirements for copper in tilapia (6 ppm), as outlined by KEBS standards (FDKS 2010), as well as the minimum requirements for catfish (5 ppm), as specified by FAO (2017). Thus, the ACM75 diet can be used to substitute FWSM and still obtain the same or higher values of copper.

Zinc in fish is involved in many metabolic pathways, serves as a specific cofactor for various enzymes and has also been shown to assist in healing of wounds (Watanabe et al. 1997; FAO 2017). The KEBS minimum requirements for tilapia ranges between 50 and $100 \mathrm{ppm}$ depending on the stage of fish that is being targeted (FDKS 2010), while the minimum requirement for catfish is $20 \mathrm{ppm}$ (FAO 2017). The fact that all the study formulations were between 100 and $200 \mathrm{ppm}$ and that the control diet did not differ from BSFM50 and ACM75 demonstrate that BSFM and ACM can be used to substitute FWSM up to 50 and 75\%, respectively, with regard to zinc. The extrusion process has little effect on zinc composition, as the moisture content did not show significant influence on its content. Other studies have also documented the non-significant influence of extrusion on zinc and its bio-availability (Guy 2001; Kang and Chenoweth 2000).

Manganese is required in fish for normal brain functioning as well as for the metabolism of carbohydrates and lipids (Watanabe et al. 1997). The minimum requirements for manganese in feeds intended for tilapia and catfish are 12 and $2.4 \mathrm{ppm}$, respectively (FAO 2017). Findings from our study indicate that BSFM50 and ACM75 are best suited for feeding tilapia, as they contain more than $12 \mathrm{ppm}$ of manganese. However, all the formulations met the minimum requirements for manganese that is required by catfish. Manganese is one of the elements that is least affected by the extrusion process and its parameters (Razzaq et al. 2012; Singh et al. 2007), partly due to its electronic configuration that lenders it less susceptible to the formation of chelates (Alonso et al. 2001). This explains why feed moisture content did not influence the manganese content of the final products.

Iron is necessary for hemoglobin and myoglobin pigments (FAO 2017) and is actively involved in oxidation/reduction reactions (Watanabe et al. 1997). The decrease in iron content as the level of FWSM substitution with BSFM increased is attributed to the low iron content that is found in BSFM in comparison to FWSM (Table 3). Similarly, the corresponding increase in iron content as FWSM is substituted with ACM is due to the higher iron content in ACM than in FWSM (Table 3). Other researchers have also shown that ACM 
has higher iron content than BSFM (Makkar et al. 2014; Finke 2002; Barker et al. 1998). It should be noted that all the formulations exceeded the minimum iron requirements for tilapia and catfish (60 and $30 \mathrm{ppm}$, respectively) (FAO 2017; FDKS 2010). The extrusion process influenced the amount of iron in the final products where, for each formulation, the $30 \%$ feed moisture content resulted in feeds having higher iron content. This could be attributed to the fact that moisture and high temperature of the extrusion $\left(120^{\circ} \mathrm{C}\right)$ increased the abrasion of the extruder barrel, screw and the die, thereby increasing the final iron content. Similar phenomena have been reported by others (Razzaq et al. 2012; Guy 2001; Alonso et al. 2001; Camire et al. 1990).

\section{Leaching activity}

Leaching activity is determined by water stability of feeds, where pellets with low water stability exhibit higher leaching effect (Saalah et al. 2010; Ayadi et al. 2011). Irungu et al. (2018) had reported that at 30\% moisture content, ACM75- and BSFM75-based pellets had higher water stability than fish feeds that had 100\% FWSM. This explains why the control diet had higher leaching effect for most of minerals than the ACM75 and BSFM75 diets. Our findings are in agreement with those of Haghbayan and Mehrgan (2015) and Hardy (2002), who reported that fish meal in fish feed increased the nutrient load in wastewater and thus contributed to higher leaching effect. Phosphorus and sodium leaching leads to eutrophication and algal blooms (Jia et al. 2015; Xiang and Zhou 2011; Saalah et al. 2010), while lack of adequate potassium affects nerve and muscle formation in fish (Wurts 1993) and thus there is need to substitute fish meal with either ACM75 or BSFM75 meals, as the two lead to low leaching of phosphorus, sodium and potassium as compared to the control. In addition, fish do not get phosphorus readily from the water environment (Tang et al. 2012), and thus feeds that have higher phosphorus leaching activity contribute to phosphorus deficiency in fish. Calcium and magnesium leaching do not pose a serious challenge, as both contribute to water hardness which is important for the growth of fish. For example, relatively high amounts of free calcium ions in water reduce the loss of sodium and potassium salts from the body of fish (Wurts 1993). However, high concentration of hard water may increase the susceptibility of fish to columnaris disease (Avant 2015). The decreasing copper, zinc and iron leached levels in the BSFM75 diets and copper and zinc in the ACM75 and control diets, respectively, could be due to formation of complexes by the macro minerals rendering these micro elements unavailable with time.

\section{Conclusion}

Both adult cricket meal and black soldier fly larvae meal can be used to substitute freshwater shrimp meal up to $75 \%$ in fish feeds and supply both tilapia and catfish with adequate quantities of minerals such as potassium. Further studies should investigate the bio-availability of minerals for fish from these diets.

Acknowledgements This work was supported by the 'INSFEED-Insect Feed for Poultry and Fish Production in Kenya and Uganda' project (Cultivate Africa Grant no.: 107839-001), co-funded by the International Development Research Centre, Canada (IDRC) and Australia Centre for International Agricultural Research (ACIAR).

\section{Compliance with ethical standards}

Conflict of interest The authors declare that they have no conflict of interest.

Open Access This article is distributed under the terms of the Creative Commons Attribution 4.0 International License (http:// creativecommons.org/licenses/by/4.0/), which permits unrestricted use, distribution, and reproduction in any medium, provided you give appropriate credit to the original author(s) and the source, provide a link to the Creative Commons license, and indicate if changes were made. 


\section{References}

Afiukwa J, Okereke C (2013) Evaluation of proximate and mineral contents of termite (Trinervitermes germinatus) from Abakaliki and Ndieze izzi, Ebonyi state, Nigeria. Am J Food Nutr 3(3):98-104. https://doi.org/10.5251/ajfn.2013.3.3.98.104

Alam MS, Kaur J, Khaira H, Gupta K (2016) Extrusion and extruded products: changes in quality attributes as affected by extrusion process parameters: a review. Crit Rev Food Sci Nutr 56(3):445-473

Alonso R, Rubio LA, Muzquiz M, Marzo F (2001) The effect of extrusion cooking on mineral bioavailability in pea and kidney bean seed meals. Anim Feed Sci Technol 94(1):1-13

Avant S (2015) Fish reared in hard water are more susceptible to columnaris disease. United States Department of Agriculture. https://www.ars.usda.gov/news-events/news/research-news/2015/fish-reared-in-hard-water-are-more-susceptible-to-colum naris-disease/. Accessed 2 June 2017

Ayadi FY, Muthukumarappan K, Rosentrater KA, Brown ML (2011) Twin-screw extrusion processing of rainbow trout (Oncorhynchus mykiss) feeds using various levels of corn-based distillers dried grains with solubles (DDGS). Cereal Chem 88(4):363-374

Barker D, Fitzpatrick MP, Dierenfeld ES (1998) Nutrient composition of selected whole invertebrates. Zoo Biol 17(2):123-134

Barroso FG, de Haro C, Sánchez-Muros MJ, Venegas E, Martínez-Sánchez A, Pérez-Bañón C (2014) The potential of various insect species for use as food for fish. Aquaculture 422-423:193-201. https://doi.org/10.1016/j.aquaculture.2013.12.024

Belluco S, Losasso C, Maggioletti M, Alonzi CC, Paoletti MG, Ricci A (2013) Edible insects in a food safety and nutritional perspective: a critical review. Compr Rev Food Sci Food Saf 12(3):296-313. https://doi.org/10.1111/1541-4337.12014

Bondari K, Sheppard DC (1981) Soldier fly larvae as feed in commercial fish production. Aquaculture 24:103-109

Braga WF, Araújo JG, Martins GP, Oliveira SL, Guimarães IG (2016) Dietary total phosphorus supplementation in goldfish diets. Latin Amer J Aquat Res 44(1):129-136

Camire ME, Camire A, Krumhar K (1990) Chemical and nutritional changes in foods during extrusion. Crit Rev Food Sci Nutr 29(1):35-57

Chakravorty J, Ghosh S, Jung C, Meyer-Rochow VB (2014) Nutritional composition of Chondacris rosea and Brachytrupes orientalis: two common insects used as food by tribes of Arunachal Pradesh, India. J Asia Pac Entomol 17(3):407-415. https://doi.org/10.1016/j.aspen.2014.03.007

Chavez-Sanchez C, Martinez-Palacios CA, Martinez-Perez G, Ross LG (2000) Phosphorus and calcium requirements in the diet of the American cichlid Cichlasoma urophthalmus (Gunther). Aquac Nutr 6(1):1-10

Cheftel JC (1986) Nutritional effects of extrusion-cooking. Food Chem 20(4):263-283

FAO (2010) The state of world fisheries and aquaculture. FAO, Rome

FAO (2012) The state of world fisheries and aquaculture. FAO, Rome, p 209

FAO (2013) Insects as animal feed. FAO, Rome

FAO (2014) The state of world fisheries and aquaculture. FAO, Rome, p 223

FAO (2015) The state of food insecurity in the world. Meeting the 2015 international hunger targets: Taking stock of uneven progress. http://www.fao.org/3/a-i4646e.pdf. Accessed 20 Mar 2017

FAO (2016) Minerals. FAO, Rome

FAO (2017) Aquaculture feed and fertilizer resources information system. FAO, Rome. http://www.fao.org/fileadmin/user_ upload/affris/docs/North_African_Catfish/English/table_4.htm. Accessed 3 May 2017

Filipovic S, Kormanjos S, Sakac M, Filipovic J, Psodorov D, Okanovic D (2010) Effect of extrusion on nutritive value of animal feed. In 2nd workshop feed-to-food FP7 REGPOT-3. Extrusion technology in feed and food processing, Thematic Proceedings. Novi Sad, Serbia, 19-21 October, 2010. Institute for Food Technology, pp 97-116

Final Draft Kenya Standard (FDKS-2289-1) (2010) Compounded Tilapia feeds: specification. Kenya Bureau of Standards, Nairobi

Finke MD (2002) Complete nutrient composition of commercially raised invertebrates used as food for insectivores. Zoo Biol 21(3):269-285

Guy R (2001) Extrusion cooking: technologies and applications. Woodhead Publishing, Cambridge

Haghbayan S, Mehrgan MS (2015) The effect of replacing fish meal in the diet with enzyme-treated soybean meal (HP310) on growth and body composition of Rainbow trout Fry. Molecules 20(12):21058-21066

Halden AN, Lindberg JE, Masembe C (2014) Aquaculture-a fast growing food production sector. SLU Glob:42-45

Hardy RW (2002) Rainbow trout, Oncorhynchus mykiss. Nutrient requirements and feeding of finfish for aquaculture. In: Wibster CD (ed) Aquaculture research center. Aurburn, Alabama, ISD, pp 184-202

Hassaan MS, Soltan MA, Agouz HM, Badr AM (2013) Influences of calcium/phosphorus ratio on supplemental microbial phytase efficiency for Nile tilapia (Oreochromis niloticus). Egypt J Aquat Res 39(3):205-213

Henry M, Gasco L, Piccolo G, Fountoulaki E (2015) Review on the use of insects in the diet of farmed fish: past and future. Anim Feed Sci Technol 203:1-22

Irungu FG, Mutungi C, Faraj AK, Affognon H, Kibet N, Ekesi S, Nakimbugwe D, Fiaboe KKM (2018) Physicochemical properties of extruded fish feeds pellets containing black soldier fly (Hermetia illucens) larvae and adult cricket (Acheta domesticus) meals. J Insects Food Feed. https://doi.org/10.3920/JIFF2017.0008

Jahnen-Dechent W, Ketteler M (2012) Magnesium basics. Clin Kidney J 5(Suppl 1):i3-i14

Jia B, Tang Y, Tian L, Franz L, Alewell C, Huang JH (2015) Impact of fish farming on phosphorus in reservoir sediments. Sci Rep 5:16617

Kang SY, Chenoweth WL (2000) Zinc bioavailability in a semolina/soy protein mixture was not affected by extrusion processing. Nutr Sci 3(2):71-76 
Kinyuru JN, Kenji GM, Njoroge SM, Ayieko M (2010) Effect of processing methods on the in vitro protein digestibility and vitamin content of edible winged termite (Macrotermes subhylanus) and grasshopper (Ruspolia differens). Food Bioprocess Technol 3(5):778-782. https://doi.org/10.1007/s11947-009-0264-1

Makkar HP, Tran G, Heuzé V, Ankers P (2014) State-of-the-art on use of insects as animal feed. Anim Feed Sci Technol 197:1-33

Msangi S, Kobayashi M, Batka M, Vannuccini S, Dey MM, Anderson JL (2013) Fish to 2030: prospects for fisheries and aquaculture. World Bank Report (83177-GLB)

Murphy SP, Allen LH (2003) Nutritional importance of animal source foods. J Nutr 133(11):3932S-3935S

Mutungi C, Irungu FG, Nduko J, Mutua F, Affognon H, Nakimbugwe D, Ekesi S, Fiaboe KKM (2017) Postharvest processes of edible insects in Africa: a review of processing methods, and the implications for nutrition, safety and new products development. Crit Rev Food Sci Nutr. https://doi.org/10.1080/10408398.2017.1365330

National Research Council (US)-Subcommittee on Fish Nutrition (1993) Nutrient requirements of fish. National Academy Press, Washington DC, p 114

National Research Council (US)-Subcommittee on Fish Nutrition (2011) Nutrient requirements of fish and shrimp. National Academy Press, Washington DC

Newton GL, Booram CV, Barker RW, Hale OM (1977) Dried larvae meal as a supplement for swine. J Anim Sci 44(3):395-400

Nielsen SS (2010) Food analysis. Springer, New York, p 550

Nikmaram N, Kamani MH, Ghalavand R (2015) The effects of extrusion cooking on anti-nutritional factors, chemical properties and contaminating micro-organisms in food. Int J Farm Allied Sci 4(4):352-354

Njagi KA, Njati IC, Huka GS (2013) Factors affecting profitability of fish farming under economic stimulus program in Tigania East District, Meru County, Kenya. IOSR J Bus Manag 15(3):25-36

Oliva-Teles A (2012) Nutrition and health of aquaculture fish. J Fish Dis 35(2):83-108

Oonincx DG, van Itterbeeck J, Heetkamp MJ, van den Brand H, van Loon JJ, van Huis A (2010) An exploration on greenhouse gas and ammonia production by insect species suitable for animal or human consumption. PLoS One 5:e14445

Razzaq MR, Anjum FM, Khan MI (2012) Effect of extruder variables on chemical characteristics of maize (Zea mays L.) extrudates. Pak J Food Sci 22(2):108-116

Rumpold BA, Fröhling A, Reineke K, Knorr D, Boguslawski S, Ehlbeck J, Schlüter O (2014) Comparison of volumetric and surface decontamination techniques for innovative processing of mealworm larvae (Tenebrio molitor). Innov Food Sci Emerg Technol 26:232-241

Saalah S, Shapawi R, Othman NA, Bono A (2010) Effect of formula variation in the properties of fish feed pellet. J Appl Sci 10(21):2537-2543

Singh S, Gamlath S, Wakeling L (2007) Nutritional aspects of food extrusion: a review. Int J Food Sci Technol 42(8):916-929

Tang Q, Wang C, Xie C, Jin J, Huang Y (2012) Dietary available phosphorus affected growth performance, body composition, and hepatic antioxidant property of juvenile yellow catfish (Pelteobagrus fulvidraco). Sci World J 2012:1-9

Tessenderlo G (2005) The role of phosphorus in the nutrition of Salmond fish. Tessenderlo Group, Brussels

Thompson KR, Muzinic LA, Engler LS, Webster CD (2005) Evaluation of practical diets containing different protein levels, with or without fish meal, for juvenile Australian red claw crayfish (Cherax quadricarinatus). Aquaculture 244(1):241-249

Trumpo P, Yates AA, Schlicker S, Poos M (2001) Dietary reference intakes: vitamin A, vitamin K, arsenic, boron, chromium, copper, iodine, iron, manganese, molybdenum, nickel, silicon, vanadium and zinc. J Am Diet Assoc 101(3):294-301

Tumuluru JS (2014) Effect of process variables on the density and durability of the pellets made from high moisture corn stover. Biosyst Eng 119:44-57

Tumuluru JS, Wright CT, Hess JR, Kenney KL (2011) A review of biomass densification systems to develop uniform feedstock commodities for bioenergy application. Biofuels Bioprod Biorefin 5(6):683-707

Van Huis A (2013) Potential of Insects as food and feed in assuring food security. Annu Rev Entomol 58(1):563-583

Watanabe T, Kiron V, Satoh S (1997) Trace minerals in fish nutrition. Aquaculture 151(1):185-207

Webster CD, Lim C (2002) Nutrient requirements and feeding of finfish for aquaculture. CABI Publishing, UK

Wurts WA (1993) Understanding water hardness. World aquaculture 24(1):18

Xiang SL, Zhou WB (2011) Phosphorus forms and distribution in the sediments of Poyang Lake, China. Int J Sedim Res 26(2):230-238

\section{Publisher's Note}

Springer Nature remains neutral with regard to jurisdictional claims in published maps and institutional affiliations. 